\title{
"Edificando um Patrimônio Sentimental": O Clube Social 24 de Agosto e seu reconhecimento cultural pelo Estado do Rio Grande do Sul
}

\author{
“Construyendo un Patrimonio Sentimental”:El Club 24 de Agosto y su \\ reconocimiento cultural pelo Estado del Río Grande del Sur
}

\author{
1Juliana dos Santos Nunes \\ 1jujukanunes@gmail.com, Universidade Federal de Pelotas.
}

\begin{abstract}
Resumo
O presente artigo tem a finalidade de trazer a pesquisa realizada para o processo de reconhecimento patrimonial do Clube 24 de Agosto junto ao IPHAE, bem como a importância dessa instituição social para a comunidade negra urbana jaguarense no começo do século vinte até o presente.

Palavras-chave: patrimônio material e imaterial, clube social negro, imprensa jaguarense, transitividade de espaços;

This article is intended to bring the research conducted for the asset recognition process Club August 24 with the IPHAE as well as the importance of this social institution for urban black community jaguarense at the beginning of the twentieth century to the present.

Keywords: Intangible Heritage and material, black social club, jaguarense press, spaces of transitivity;
\end{abstract}

\section{Clube Social 24 de Agosto na Lembrança dos Frequentadores}

A importância da formação de uma sociedade bailante de caráter étnico para a cidade de Jaguarão sem sombra de dúvidas é reconhecida na contemporaneidade. Entretanto, não podemos ter nossa mirada posta na história de maneira simplista: é preciso haver uma justificativa para essa importância.

Além dessa importância, dentro de um contexto amplo, no qual os negros e seus descendes foram excluídos dos meios sociais (aqui acrescentamos os meios educacionais, políticos, econômicos e trabalhistas), e no qual ressaltamos a especificidade de uma cidade de fronteira, onde os princípios positivistas e católicos foram, sobremaneira, utilizados para justificar uma nova moral que surgia nos primeiros anos republicanos. Neste sentido, a particularidade situa-se na intensa transitividade de pessoas e culturas, mas não há uma mudança de mentalidade do resto do país.

Dessa forma, para o caso da cidade em estudo, verificamos políticas de doutrinação dos negros, através do Círculo Operário de Jaguarão - antiga Sociedade Operária Jaguarense - 
, e a entrada desses homens em um mercado de trabalho, não muito favorável e a uma lógica capitalista industrial, o que correspondia com o restante do país. Além do mais, o fato de não poderem se associar a um Clube, já prova a exclusão e escamoteamento desses recém-libertos da cidade de Jaguarão.

Para ilustrar essa situação, nos reportamos a uma lembrança do Mestre Vado, músico dos cordões e frequentador do Clube 24 de Agosto desde os 12 anos de idade, quando desfilou pela primeira vez no Cordão União da classe:

“[...] no clube sim tinha distinção, tinha o clube dos brancos e tinha o clube dos negros e o 24 era chamado o clube da raça [...] tinha, tinha muito preconceito. No Harmonia, para entrar no Harmonia ${ }^{l}$ tinha que ser com uma pessoa de bem, com muita recomendação, filho de fulano, filho de cicrano, e tinha o Jaguarense $e^{2}$ que era um pouquinho menos e tinha o 24 que aí sim, era só negro, branco não entrava e nem o negro não entrava no do branco, era assim, tinha distinção de cor." (Entrevista concedida por Mestre Vado em junho de 2008 realizada na sua residência).

Nessa narrativa, Vado deixa evidente a exclusão social dos negros na sociedade urbana de Jaguarão em meados do século XX, ao mesmo tempo em que mostra a importância do Clube 24 para essa comunidade situada à margem dos acontecimentos sociais.

Além do mais, Vado ressalta a característica étnica do Clube 24 ao colocar que: “[...] tinha o 24 que aí sim era só negro, branco não entrava e nem o negro não entrava no do branco [...]" e isso prova o quão fundamental foi esse clube para a formação social dos negros jaguarenses no perímetro urbano, na primeira metade do século XX.

Não somente Mestre Vado traz consigo essa consciência de pertencimento a esse espaço, como também Nergipe Machado, que desde os dez anos frequenta o clube, considerando a sua fundação como um feito dos antigos negros que o ajudaram a ser "um cidadão social". Em sua narrativa, Nergipe também deixa clara a exclusão sofrida pelos negros que residiam na zona urbana da cidade, nas suas palavras:

[...] esses amigos acharam por bem fundar uma sociedade por não ter razão de onde levar a família, que na época o negro não participava de clube nenhum, que

1 Sociedade Harmonia Jaguarão é uma instituição tradicional ligada à elite branca jaguarense. Atualmente há uma abertura maior para as demais classes sociais, diverso do que ocorria na época em que Mestre Vado começou sua carreira musical.

2 Clube Social Cruzeiro Jaguarense, também é uma instituição ligada à elite branca jaguarense. 
eles só tinham as casas de família que formavam brincadeiras e assim se divertiam [...] (Entrevista concedida por Nergipe Machado em 2009 realizada na sua residência.).

Ao nos contar sua trajetória pessoal dentro do clube 24, Nergipe revela as formas de divertimento e sociabilidade dos negros antes de possuírem um espaço destinado às confraternizações. Dessa forma, percebemos a origem familiar da instituição e acima de tudo, o regime de separação étnico/social ao exprimir que "negro não participava de clube nenhum".

Ainda se tratando da narrativa de Nergipe, notamos a exaltação das figuras responsáveis pelo aparecimento do Clube 24 de Agosto, ao nos dizer que "esses amigos acharam por bem fundar uma sociedade"; destacamos esse excerto, pois Nergipe irá tratar de maneira respeitosa e até mesmo mítica, a pessoa de Theodoro Rodrigues, apontado por muitos frequentadores e sócios como o principal fundador do Clube 24.

As memórias dos sócios mais antigos do 24 vêm carregadas de um sentimentalismo, fazendo de suas narrativas um texto emocionante, na medida em que percebemos a relação destas pessoas com o espaço - e aqui incluímos sua identificação e sua pertença a um grupo étnico e social - e com os fundadores, visto e descritos de maneira heróica e mítica. Essa abordagem não será aprofundada nesse texto, entretanto, cabe ressaltar a imagem que se criou desses homens que tiveram a iniciativa de fundar uma sociedade para sua própria comunidade.

Para dar mais um exemplo desse sentimento de pertença, transcrevemos a narrativa de D. Tereza de los Angeles, na qual nos relata seu vínculo com a instituição desde criança e sua recordação remonta aos antigos carnavais dos cordões carnavalescos do Clube:

Nós éramos bem novas, uns dez anos, e eles iam ${ }^{3}$ ali na 27, nas casas desses ricos. Naquela época eles esperavam quando chegava o União com aquelas mesadas de doces e frios e entravam tudo para dentro das casa desses gran finos. E tinha o livro de ouro. E nós adorávamos por que era aqui, ali onde é a casa da Norma, na esquina, é nós esperávamos, mas era uma beleza quando entrava clube adentro e comiam e serviam, tocavam, mas era uma beleza! (Entrevista concedida por Tereza de los Angeles, em 2009, realizada na sua residência).

3 Fazendo referência ao Cordão União da Classe que pertenceu ao Clube 24 de Agosto. 
Aqui D. Tereza, além de relatar sua participação no clube desde tenra idade, conta um pouco da dinâmica evolutiva dos cordões carnavalescos, da beleza dos carnavais de outrora. Seu sentimento de pertença a esse espaço fica evidente ao exaltar seus feitos carnavalescos e sua presença nessa instituição por um longo período de tempo; Hoje, D. Tereza é sócia benemérita do Clube 24 e continua frequentando as atividades realizadas no clube, em especial os bailes de aniversário.

Há que se comentar que D. Tereza tem uma grande estima pela presença feminina dentro do Clube, pois foi ela quem guardou a maior parte das fotografias das rainhas do 24 , as quais foram doadas para essa pesquisa e para o Clube constituir seu acervo histórico.

Dizemos isso para contrapor a história dominante vista pelo olhar masculino e sob sua égide; entretanto, não podemos agir com anacronismos, pois a história que chegou no "presente" está cheia de registros que exaltam as figuras dos fundadores homens; há sim que se relativizarem os "olhares" sobre esse papel masculino e incluir as mulheres como pertencentes à construção social do negro no contexto urbano na cidade de Jaguarão, e não apenas como uma excluída e, quiçá, vítima da história.

Outra narrativa feminina que deixaremos registrada nesse artigo é a de D. Cibele de Oliveira, filha de uma dos fundadores do Clube, Malaquia de Oliveira. Ela fala com orgulho de sua trajetória, dos feitos de seu pai e de como ajudou na construção da sede atual do 24 . Entretanto, o que mais chama atenção na sua narrativa é a identidade étnica exaltada, ao comentar que para ela a causa do clube 24 está ligada à figura do negro e aos quilombos:

Vou começar assim, o negro, que isso é mais uma luta do negro, não tinha onde dançar só se fizesse assim uma festa, um baile de aniversário, e um determinado grupo de cavalheiros, aonde meu pai era um deles, se reuniram e resolveram fundar o Clube 24 [...] e se tiver que tombar que tombem e façam um museu dos quilombolas. (Entrevista concedida por Cibele de Oliveira, em 2009, realizada na residência de Neir Madruga Crespo).

Nesse trecho D. Cibele deixa transparecer seu sentimento de pertença étnica àquele espaço, o qual considera um quilombo. Pensando nessa perspectiva, podemos considerar o Clube como um espaço de liberdade e não somente de resistência no período pós-abolição. Esse período tem como marco inicial o fim da escravidão, com a assinatura da Lei Áurea em 1888, e a imediata situação dos libertos, com a passagem de sua condição de escravos para cidadãos trabalhadores inserindo-se na nova sociedade brasileira. 


\section{O Clube 24 de Agosto na Imprensa Jaguarense do Século XX e a Transitividade de}

\section{Espaços}

Atualmente, todos sabem a importância de se valorizar e preservar uma instituição como o Clube 24 de Agosto, não somente por sua longevidade no tempo, e isso também tem sua carga de relevância para história, mas pelo fato histórico, social, político e cultural, que representou à época de sua fundação, e no presente, pelo sentido de continuidade à luta contra o preconceito étnico racial, principiada por aqueles antigos homens e mulheres que foram impedidos de se divertir em sociedade por conta da cor da sua pele. Lembramos que a sociedade 24 de Agosto foi fundada no começo da chamada República Velha brasileira, que se constituía sob o "manto" do positivismo, calcado nas políticas de homogeneização cultural; foi um período marcado pelo fortalecimento das políticas raciais, com a publicação de diversas obras que versavam sobre a situação do negro no Brasil, dentre as quais, destacamos Casa Grande \& Senzala, de Gilberto Freyre.

O escamoteamento do negro dos meios sociais, culturais, trabalhistas e políticos e sua invisibilidade histórica não o impediram, entretanto, de se organizar tanto politicamente, quanto culturalmente, como bem refere Loner (1996) em pesquisa sobre a classe operária nas cidades de Pelotas e Rio Grande, na qual, a autora supracitada, com vasta produção sobre a temática, coloca o negro como um “operário por excelência”.

Dessa forma, ao aprofundar nossos estudos encontramos a maior parte dos fundadores do Clube 24 associados ao Círculo Operário ${ }^{4}$ Jaguarense. Isso ocorreu devido às políticas educacionais, pois de acordo com Sidney Chalhoub: "a transformação do liberto em trabalhador não podia se dar apenas através da repressão, da violência explícita [...] era necessário educar os libertos" (Chalhoub 2001, p. 69). Esse papel de "educador" da comunidade afro-jaguarense bem o fez a Sociedade Operária, dando-lhes, ao mesmo tempo, condições de sociabilidade entre o grupo, culminando com a fundação de um Clube especialmente para os negros.

A transitividade entre os espaços - trabalhista e social - pode ser vista em um convite recebido pela Sociedade Operária Jaguarense para participar do baile de aniversário do Clube 24:

Sociedade Operária Jaguarense em sessão de três de agosto de 1922 tendo número legal de diretores o senhor presidente deu por aberta a sessão, apresentando um ofício do Clube 24 de Agosto convidando para comparecerem em seu aniversário

\footnotetext{
4 A designação de Círculo Operário se dará mais tarde, por volta da década de 1950, antes desse período, era
} designada como Sociedade Operária Jaguarense. 
deste mesmo dia em sua sede na Rua 20 de Setembro dez horas da noite para assistirem suas festas. (grifo nosso)

Além desse convite, o 24 de Agosto também comunicou à Sociedade Operária a constituição de sua nova diretoria, conforme ofício expedido pelo Clube:

Aos quinze dias do mês de agosto de 1920 foram lidos dois ofícios, um da sociedade Caixeral Jaguarense, comunicando a eleição de nova diretoria, que será empossada no dia 3 de setembro e outro do Club 24 de Agosto comunicando também a posse de sua nova diretoria e ao mesmo tempo convidando a sociedade para se fazer representar no dia 24 de agosto. (grifo nosso)

Esses ofícios são significativos para mostrar a transitividade entre esses espaços; entretanto esses mesmos documentos seriam inúteis se não tivéssemos em mente que os membros fundadores do Clube 24 de Agosto faziam parte da Sociedade Operária inclusive como diretores, como foi o caso de Theodoro Rodrigues que participou como bibliotecário e também como presidente dessa mesma instituição.

Essa transitividade também se deu no campo religioso, e nesse sentido, destacamos a presença, desses mesmos fundadores do Clube 24, na Irmandade de Nossa Senhora do Rosário que pertenceu à igreja Matriz do Divino Espírito Santo, fundada em 1860. Theodoro Rodrigues, por exemplo, participou como festeiro da Irmandade por diversas vezes.

Ainda há muito que se explorar sobre essa relação, mas para o caso em estudo, podemos afirmar que ela existiu e proporcionou a sociabilidade dos negros, por meio das inúmeras atividades realizadas pela irmandade, e, também, pela a atuação política com formação de um montepio para a compra de cartas de alforria, como bem descreveram Franco \& Soares ao transcrever trechos do diário do Cônego Thomas Aquinas Schoenaers, observador do cotidiano jaguarense na primeira metade do século XX:

A Irmandade do Rosário, exclusivamente composta de negros, realizou sua grande festa no último domingo do ano, dia 29 de dezembro. Já oito dias antes das festividades, grande número de negros desfilava pelas ruas com suas melhores roupas, encabeçadas pelo corpo musical e sob a bandeira de Nossa Senhora do Rosário. (Schoenaers apud Soares \& Franco, 2010, p. 85).

Esse excerto é ilustrativo da transitividade dos afro-jaguarenses no meio católico, sendo que esses mesmos descendentes dos antigos escravos estiveram na formação não somente do Clube 24, mas também da Sociedade Operária. Essa afirmação se fundamenta quando encontramos os mesmos sujeitos associados nas três instituições em questão: Clube 24 de Agosto, Sociedade Operária e Irmandade de Nossa Senhora do Rosário. 
Esse trânsito entre as sociedades citadas é emblemático para mostrar o grau de associativismo $^{5}$ desses homens e mulheres negros, que tentavam, à sua maneira, burlar o preconceito étnico sem, contudo, deixar de lado seu sentimento de pertença.

A transitividade ultrapassou os limites da cidade, pois de acordo com as atas de 1955, o 24 de Agosto recebeu correspondências de outras agremiações para participar de diversas atividades, damos destaque aqui para a Escola de Samba Bambas da Orgia de Porto Alegre e para a Escola de Samba General Vitorino de Rio Grande, sendo que esta última fez um pedido de visitação à sede agostiniana, mas, encontrando-se em dificuldade financeira, o clube não teve como arcar com as despesas da Escola riograndina.

No que diz respeito às notícias vinculadas na imprensa sobre o Clube 24, podemos dizer que existe uma grande profusão de dados - aqui é preciso esclarecer, que, os documentos produzidos pelo próprio clube que chegaram ao presente, dizem respeito a um conjunto de $\operatorname{atas}^{6}$, recentemente descobertos pelo atual presidente, o Sr. Neir Madruga Crespo, que abarcam os anos de 1955 até 1989 - sobre os carnavais do 24, com especial atenção ao Cordão Carnavalesco União da Classe, que animou os carnavais jaguarenses por mais de cinquenta anos.

Os jornais consultados para elaboração dessa pesquisa foram: A Situação, que abarca o começo do século XX até meados deste, e o jornal A Folha, com primeira edição datada em 1939 até os dias atuais. Entretanto, foi no jornal A Situação que trouxe maiores informações sobre o clube, muito embora pertencente à elite branca jaguarense e vinculado ao partido Libertador.

Theodoro Rodrigues foi um homem que manteve estreitos laços de amizade e de compadrio com elite, fazendo dessa relação um eixo para vincular o clube na imprensa branca. Dessa forma, é preciso relativizar as informações que constam nos periódicos, pois se tratam de reportagens produzidas pelo olhar do "outro", e este é um olhar exógeno, não somente do ponto de vista da cultura, mas, principalmente, do ponto de vista político e ideológico.

Sobre a fundação do Clube 24, esta não foi mencionada na imprensa e tampouco foi anunciado o primeiro baile de aniversário, data de suma importância para a comunidade, pois as notícias vinculadas nos jornais citados estão concentradas nos festejos de carnaval - aqui

Sobre o tema associativismo ver Oliveira (2010).

6 Deixamos aqui registrado que esse trabalho de pesquisa não teve como objeto empírico essas atas, pois foram descobertas no mês de agosto de 2011. 
nos referimos ao "ciclo carnavalesco" que engloba o pré-carnaval, um momento de preparo, o carnaval, momento da catarse anti - estrutura e o pós - carnaval, momento de retomada das atividades voltadas à festividade ${ }^{7}$ - no cordão e na orquestra deste.

No entanto, para este estudo, são relevantes os comentários sobre os festejos de carnaval do Clube 24, tendo em vista que consideramos esse evento, para a comunidade negra, como um momento de reivindicação política ${ }^{8}$. A primeira nota que vincularemos versa sobre a fundação do Cordão União da Classe e a publicação de quatro canções compostas pelos membros do clube. Isso ocorreu em 23 de fevereiro de 1924:

\section{Cordão}

Um grupo de enthusiastas associados ao club 24 de Agosto organisou um cordão carnavalesco que denominou União da Classe. Esse cordão apparecerá ao público na terça-feira gorda com excelente letra e música que estão sendo ensaiadas com muito capricho. (Jornal A Situação, fevereiro de 1924)

Quando, enfim, desfila o Cordão União da Classe, não faltaram elogios por parte da imprensa a esse folguedo:

\section{União da Classe}

O traço mais frisante de originalidade foi dado pelo bem organizado cordão União da Classe. Composto por elementos do clube 24 de Agosto, nada deixou a desejar. Primou tanto pela uniformidade de trajes como pelas composições vocalisadas com o melhor gosto de precisão. A curiosidade que despertou em nosso público foi enorme, seguindo-o, através das ruas da cidade, uma grande multidão de fantasiados e curiosos. Na frente de muitas residências cantou bons números, sendo recebido gentilmente por todos que não cessaram de lhe dispensar aplausos $e$ elogios. Muitas pessoas ofereceram-lhe brindes, entre as quais, nosso ilustre amigo o Senhor Coronel Gabriel Gonçalves da Silva que ofertou ao grupo $45 \$ 000$. (Jornal A Situação, 5 de março de 1924)

Interessante notar nesse trecho a descrição da performance $e^{9}$ de andamento na avenida, durante os dias de carnaval, do Cordão União da Classe e a popularidade deste em relação às pessoas que o assistiam. Podemos ainda destacar, dentro do campo econômico, o cortejo carnavalesco como um meio de arrecadar capital para custear o carnaval em andamento ou até mesmo para a elaboração de novas festas ao longo do ano.

$7 \quad$ Sobre esse assunto ver Prass (2004).

8 Sobre esse assunto ver Rosa (2008).

9 Quando referimo-nos a performance é levando em consideração os estudos da Antropologia da Performance. 
Nesse trecho evidenciamos o escamoteamento do negro pela imprensa ao referir os membros do clube como "elementos"; essas terminologias variavam de acordo com a situação, na qual a imagem dos negros estava vinculada a classe social operária como bem explicitado no excerto a seguir publicado no Jornal A Situação em 23 de fevereiro de 1928: "Clube 24 de Agosto. Esse apreciado Clube, composto de elemento operário, festejou também magistralmente o carnaval, tendo efetuado animados bailes." (grifo nosso).

Essa questão do operariado perpassa a história de construção de uma sociedade negra em Jaguarão, e pode ser comparada com o estudo de caso realizado por Frigerio (1993) na Argentina, tendo como contexto as comparsas de candombe, no qual este autor trata a classe no seu sentido coletivo: “A expressão classe quer dizer ser negro, de cor; e a classe implica a coletividade em seu conjunto" (Frigerio, 1993, p. 4).

Neste sentido, no termo classe está embutida a questão étnica; porém, não estamos aqui tratando de meras terminologias, pois a relevância desse fato consiste no sentido de coletividade denotada na questão da classe, e esta por sua vez, carrega o significado étnico e isso percebemos na estrutura do Clube 24 de Agosto.

Ainda sobre o papel da imprensa em relação ao Clube 24, nos deparamos com interessante notícia, quando ocorre a troca do nome do Clube, designando-o de "Clube Democrático" como mostra trecho da reportagem do jornal A Folha de 1950: "[...] Também realizaram animados bailes à fantasia em suas sedes os Clubes "Instrução e Recreio" e Democrático (ex-24 de Agosto)”. Essa mudança diz respeito à tentativa de agregar no seio da sociedade todos os tipos de pessoas, sem discriminação étnica, diferentemente do que ocorreu com os negros no começo do século XX.

Esse fato também está na lembrança de D. Cibele: "Naquela época branco não podia de jeito nenhum dançar no 24, mas o 24 foi o primeiro clube, digo daqui da região, que abriu essa exceção”. Claro está que, num primeiro momento, assim como ocorreu nos salões dos clubes dos brancos, estes não podiam participar das festividades do 24 de Agosto, entretanto, como bem afirma Cibele, foi o 24 de Agosto que abriu as portas para congregação das diferentes etnias existentes na cidade.

\section{Um "Patrimônio Sentimental": O Clube 24 de Agosto Como Um Bem do Estado do Rio Grande Do Sul}

A trajetória do Clube 24 de Agosto traz consigo a história de luta da comunidade negra jaguarense impedida de frequentar os meios sociais e discriminada por sua etnia e cor de pele e, apesar das adversidades, conseguiu se unir e se associar em diversos meios. 
Hoje, o passado está presente na contemporaneidade, quando a "retórica da perda", constitui tema central das discussões acerca da "despatrimonialização" - na sua dimensão material - do Clube 24 de Agosto por conta do leilão de sua sede social em 2007, cumprindo a execução judicial de uma dívida de aproximadamente $\mathrm{R} \$ 5.000,00$ com o Ecad.

Qual seria a melhor maneira de preservar 93 anos de história? O que preservar dessa instituição e por que salvaguardar a memória do Clube 24 de Agosto? Algumas dessas perguntas impulsionaram a mobilização da própria comunidade em torno de seu bem, percebendo-o como parte, não só de suas trajetórias individuais, mas como um bem da coletividade e, portanto, da cidade de Jaguarão.

Dessa forma, desde a execução leilão, uma série de ações vem sendo realizadas para reverter esse processo, desde trabalhos acadêmicos, no campo da história e antropologia, como também a mobilização do movimento clubista negro e a inserção do Clube 24 a este, até ações em parceria com os órgãos públicos, e aqui daremos destaque à atuação do Prefeito de Jaguarão, Cláudio Martins, que desde o início dessa trajetória, ainda nos seus tempos de vereança, vem apoiando essa comunidade, dentro da qual se coloca como integrante.

É inegável que estamos diante de um patrimônio e, dessa forma, passível de ser tombado como um bem do Estado do Rio Grande do Sul. Entretanto, não devemos ser reducionistas, pois ao afirmarmos essa condição, devemos sempre levar em consideração a trajetória da instituição e das pessoas que fazem e fizeram parte do clube, no caso estudado.

Jaguarão, considerada a cidade heroica, está situada na fronteira uruguaia, ao sul do Rio Grande do Sul, uma cidade com um passado de pujança histórica e arquitetônica: as portas da Rua Quinze de Novembro, a Matriz do Divino Espírito Santo, a Ponte Internacional Mauá, o antigo hotel Susine, nítido na memória sentimental de muitos jaguarenses, as antigas charqueadas e as ruínas da enfermaria militar fascinam os que por lá vivem e aqueles que estão de passagem.

Depois de um longo período de esquecimento, o contexto atual se mostra otimista no que tange à preservação dos bens arquitetônicos que ainda se encontram "vivos" e à valorização da história local. Nesse ano de 2011 comemora-se o tombamento, pelo IPHAN, do centro histórico de Jaguarão. Entretanto, ao passo que esse tombamento vem ao encontro das políticas para a valorização da cidade, este deixou de fora a contribuição de diferentes povos à sociedade jaguarense. O esforço de preservar o patrimônio arquitetônico e histórico jaguarense começa na década de 1980, que, de acordo com Lima foi:

Através do "Projeto Jaguar" - um convênio entre a Fundação Nacional PróMemória, a prefeitura jaguarense e a Universidade Federal de Pelotas, com uma 
equipe composta, em sua maioria, por acadêmicos e professores da faculdade de Arquitetura e Urbanismo - foi realizado pioneiramente o exaustivo trabalho de levantamento fotográfico, estudo e catalogação, com mais de seiscentas fichas de cadastro, dos prédios da cidade. Estabeleceram-se, ainda, posturas para a conservação de seu conjunto histórico. (Lima, 2010, p. 27).

Acrescentando, a mesma autora afirma que, embora tenha se feito um esforço para a preservação do conjunto histórico da cidade, este, por sua vez teve enfoque na "história dos padrões estéticos das construções e planos para a preservação da cultura material, com ênfase maior, para as classes abastadas." (Lima, 2010, p. 28).

A constituição de um patrimônio elitizado, como bem afirma a autora supracitada, é uma "visão construída de acordo com critérios políticos de seleção". E mais que isso, traz consigo a concepção ideológica de determinada classe social e nela estão implícitas as relações de poder: "o patrimônio é uma construção social coletiva, revestido por redes de significados e inclui relações de poder intrínsecas à própria construção de patrimônio". (Escobar, 2010, p 81).

Neste sentido, percebemos os motivos da não inclusão de certos bens na construção do patrimônio jaguarense que hoje é nacional: ainda estão em pauta os "velhos" jogos de poder da elite, a qual quer garantir seu papel de construtor único da sociedade, sem levar em consideração a diversidade da sociedade brasileira. Isso pode ser comprovado, pela trajetória de preservação patrimonial, iniciada em Jaguarão, em meados da década de 1980, e que se reproduziu na atualidade. Estamos aqui falando de mais de vinte anos de discussões acerca de uma valorização inclusiva.

Assim, a tentativa de incluir o Clube 24 de Agosto, à nível nacional, quando do processo de elevação de 600 bens a patrimônio histórico nacional, foi descartada por se entender que não deveríamos "banalizar" o instrumento do tombamento.

O Clube 24, então, fez um pedido formal de abertura de processo de tombamento ao IPHAE, órgão de preservação patrimonial do Estado do Rio Grande do Sul, que atendeu a demanda, visto que se sensibilizou com a história e memória da comunidade negra vinculada a este clube, e também por compreender a necessidade de valorização das diversas etnias que constituem a sociedade brasileira como um todo.

Portanto, esse artigo vem para justificar o tombamento do Clube 24 de Agosto, em seu sentido imaterial e sentimental, como bem afirmaram alguns integrantes do IPAHE em visita à sede social do clube. Muito embora não possua, na íntegra, sua documentação, e isso cause uma lacuna temporal no que tange aos registros escritos, entendemos que todo patrimônio é 
"constituído de testemunhos" (Hartog, 2006, p. 269) e por sua vez, foram os testemunhos "vivos" dessa história que estão dando a justificativa maior para o tombamento de seu bem.

Gostaríamos de reforçar essa justificativa com o depoimento de Nergipe Machado, mostrando seu envolvimento com o Clube e sua trajetória de vida, entrelaçada, por assim dizer, nas paredes daquela sede, a qual ajudou a construir no final da década de 1970:

Eu ali me formei um cidadão social, porque eu não tive raízes sociais, então eu me fiz sozinho na sociedade [...] eu agradeço a esses velhos que ainda existiam e que me ensinaram a ser um cidadão social, e assim eu me criei ali dentro, me formei moço, me casei, criei filho, criei neto, já tô agora criando bisneto, dentro do 24. (entrevista concedida por Nergipe Machado)

O conteúdo emocional da narrativa de Nergipe se torna pontual, na medida em que podemos utilizá-lo como exemplo das inúmeras trajetórias de vidas, similares a dele, dentro do Clube 24 de Agosto. Mais do que isso, essa narrativa está cheia de pretensões políticas, sociais e culturais, pois esse não é somente um discurso endógeno, mas ao contrário, é exógeno, pois mostra a vivência e envolvimento de um cidadão que percebe a importância dessa sociedade para a sua formação enquanto homem e ser social. $\mathrm{O}$ mesmo sentimento de pertença pode ser encontrado na narrativa de Cibele, ao contar com orgulho do tempo em que se uniu a outras mulheres da sociedade para fazer "massa" e colocar o parquet da atual sede:

A massa para colocar o parquet as mulheres, ficavam o dia inteirinho, uma levava arroz, outra levava óleo, outra levava carne ou levavam galinha a gente tinha um fogão, mas eu não sei, a gente fazia uma panelada de comida e todos comiam ali e os homens trabalhando e as mulheres, a gente fazia massa assim que nem homem e carregava de balde para eles não perderem tempo de colocar o parquet, por que tinha um baile e tinha que estar com o parquet, o que era pedreiro, pedreirava, mas no fim todo mundo era pedreiro, era tão lindo, tão lindo, tão lindo! (Entrevista concedida por Cibele de Oliveira, em 2009, realizada na residência de Neir Madruga Crespo).

Entendemos que a preservação desse bem também passa por sua dimensão material: "não bastam para garantir a salvaguarda e proteção para o patrimônio imaterial, posto que a natureza imaterial do bem cultural não existe em si. Ela é indissociável de uma [...] natureza material." (Viana, 2008, p. 81). Sobre esse mesmo tema, Fonseca afirma que: "todo signo (e não apenas os bens culturais) tem dimensão material (o canal físico de comunicação) e simbólica (o sentido, ou melhor, os sentidos)" (Fonseca, 2003, p. 65).

Portanto, o tombamento deve também ser pensado em sua dimensão material, visto que as lembranças são ativadas, no presente, a partir de um elo dessas pessoas com esse 
espaço, seja afetivamente, como demostrado nas narrativas acima, seja por representar a coletividade negra jaguarense, que vê nesse clube um propulsor para expressar sua cultura.

$\mathrm{Na}$ iminência de perder a sede social do clube, a comunidade agostiniana tomou consciência de sua própria coletividade, enquanto etnia negra e, militando desde esse momento no movimento clubista negro, viu na via patrimonial uma alternativa para salvaguardar a sua história, sua memória e os feitos dos fundadores. Assim o tombamento foi um "recurso para o tempo de crise" como afirma Hartog.

Atualmente, podemos afirmar que o Clube 24 de Agosto passou a ser identificado como um patrimônio para muitos jaguarenses, ou seja, saiu de sua esfera particular e passou a ser reconhecido como uma "paisagem de história [...] identificado tanto pelas populações envolvidas quanto por especialistas" (Arantes, 2004, p. 12). Nessa citação, Arantes inclui os especialistas, e da mesma forma, o Clube 24 de Agosto foi tema de trabalhos acadêmicos e pesquisas em torno de sua historicidade enquanto bem patrimonial.

Além do mais, a patrimonialização de um clube social negro traz consigo a autonomia de uma comunidade afroamericana, sendo o contraponto de uma sociedade que ainda insiste em priorizar os bens de "cal e pedra" ligados a uma elite política, econômica, cultural brasileira. Ter um espaço étnico reconhecido como um bem de um Estado é uma "demonstração de poder político" da cultura afro-brasileira e especialmente afro-gaúcha. (Nogueira, 2008, p. 243).

Portanto, compreendemos a importância desse tombamento, tanto na sua dimensão imaterial, pelo envolvimento das pessoas citadas nesse texto e tantas outras que tem sua trajetória de vida diretamente vinculada a essa instituição, suas histórias e memórias, a formação da identidade negra na cidade de Jaguarão, como na sua dimensão material, pelo fato de a sede social ser a propulsora no processo de estimular as lembranças, por ser um espaço político e de reivindicação étnica, e por permitir a livre expressão cultural afrobrasileira sem, entretanto, desrespeitar as diferenças de credo, cor ou etnia.

\section{Referências Bibliográficas}

ALBIN, Ricardo Cravo. Dicionário Houaiss Ilustrado da Música Popular Brasileira. Editora Paracatu, Rio de Janeiro, 2006.

ALFARO, Milita. Memorias de La Bacanal. Vida y milagros Del carnaval montevideano (1850-1950). Ediciones de La banda oriental, Montevideo, 2008. 
ARANTES, Antônio. O patrimônio imaterial e a sustentabilidade de sua salvaguarda. Resgate, 2004.

BAKHITIN, Mikhail. A Cultura Popular na Idade Média e no Renascimento. Hucitec, São Paulo, 2008.

BARTH, Frederik. Grupos étnicos e suas fronteiras. In: POUTIGNAT \& STREIFFFENART. São Paulo: Editora da Unesp, 1998.

BARRETO, Álvaro. Dias de Folia: o carnaval pelotense de 1890 a 1937. Pelotas: Educat, 2003.

BITTENCOURT, José. Jongo o avô do samba. Caderno Virtual de Turismo, vol. 2, Rio de Janeiro, 2002.

CANCLINI, Nestor García. Noticias recientes sobre la hibridación. Universidade Autônoma Metropolitana, México: Revista Transcultural de Música, 2003.

CARVALHO, A. P. C.. $O$ "Planeta": apontamentos sobre a invisibilidade dos negros no RS e seus reflexos no campo da cidadania. Humanas (Porto Alegre), v. 26/27, p. 179-191, 2005.

CARVALHO, José Jorge de. Um panorama da música afro-brasileira, parte I dos gêneros tradicionais aos primórdios do samba. Série Antropologia, 275, Brasília, 2000.

CHALHOUB, Sidney. Trabalho, lar e botequim. Editora Unicamp, São Paulo, 2001.

COSTA, Sérgio. A construção sociológica da raça no Brasil. Revista de Estudos AfroAsiáticos, ano 24, p. 35-61, 2002.

DAMATTA, Roberto. Carnavais, malandros e heróis: para uma sociologia do dilema brasileiro. Editora Rocco. Rio de Janeiro, 1997.

DAWSEY, John. Turner, Benjamim e a antropologia da performance. Campos 7 (2): 17-25, 2006.

Victor Turner e antropologia da experiência. Cadernos de Campo, nº 13: 163176, 2005.

DINIZ, André. O Almanaque do Samba. Editora Jorge Zahar. Rio de Janeiro, 2006. Almanaque do Carnaval. Editora Jorge Zahar. Rio de Janeiro, 2008.

DOMINGUES, Petrônio. Uma História não Contada, cap. 5: O ideal de Branqueamento, p. 253-300, SENAC, São Paulo, 2004.

ESCOBAR, Giane. Clubes sociais negros: lugares de memória, resistência negra, patrimônio e potencial. Dissertação de mestrado apresentada ao programa de pós-graduação em patrimônio cultural da Universidade de Santa Maria, Santa Maria, 2010.

FILHO, Wilson Trajano; O Auto de Carnaval em São Tomé e Príncipe: Fato e Texto. Série Antropologia 124, Brasília, 1992. 
FINNEGAN, Ruth. O que vem primeiro: O texto, a música ou a performance? Palavra cantada: ensaios sobre a poesia, música e voz. MATOS, Cláudia N.; TRAVASSOS, Elizabeth; MEDEIROS, Fernanda (org.). Rio de Janeiro, Viveiros de Castro Editora, 2008.

FRANCO, Sérgio da Costa. Gente e Coisas da Fronteira Sul. Ensaios Históricos. Editora Sulina, Porto Alegre, 2001.

FRANCO, Sérgio da Costa; SOARES, Eduardo Álvares de Souza (orgs.).

Olhares sobre Jaguarão. Porto Alegre: Evangraf, 2010.

FRIGERIO, Alejandro. El Candombe Argentino: Crónica de una morte anunciada. Revista de Investigaciones Folklóricas, faculdade de Filosofia y Letras - Universidade de Buenos Aires, 1993.

FRY, Peter. A persistência da raça. Ensaios antropológicos sobre o Brasil e a África austral. Editora Civilização Brasileira, Rio de Janeiro, 2005.

FONSECA, Maria Cecília Londres. Para além da pedra e cal: por uma concepção ampla de patrimônio cultural in: Memória e Patrimônio: ensaios contemporâneos. ABREU, Regina e CHAGAS, Mário. Rio de Janeiro, 2003.

FOOTE-WHYTE. Willian. “Treinando a observação participante.” In: A. Zaluar (org.) Desvendando Máscaras Sociais. Francisco Alves Editora, Rio de Janeiro, 1975.

GERMANO, I. G. Rio Grande do Sul, Brasil e Etiópia: os negros e o carnaval de Porto Alegre nas décadas de 1930 e 40. Dissertação de mestrado apresentada ao programa de pósgraduação em História da UFRGS, Porto Alegre, 1999.

GILL, Lorena; LONER, B. A.. Os clubes carnavalescos negros de Pelotas. In: $3^{o}$ encontro escravidão e Liberdade no Brasil Meridional. Florianópolis, 2007.

GOMES, Fabrício. Sob a proteção da princesa e de São Benedito: Identidade étnica, associativismo e projetos num clube negro de Caxias do Sul (1934-1988). Dissertação de mestrado apresentada ao programa de pós-graduação em História da Unisinos, São Leopoldo, 2008.

GONÇALVES, Renata de Sá. Ranchos Carnavalescos e o Prestígio das Ruas: territorialidades e sociabilidades no carnaval carioca da primeira metade do século XX. Textos escolhidos de cultura e arte populares. Rio de Janeiro, n. 1. p. 71-80, 2006.

GUTERRES, Liliane. La gente de Ansina. Performance, tradição e modernidade no carnaval da "comparsa de Negros e Lubolos Sinfonía de Ansina" em Montevideo/Uruguay. Tese de doutorado apresentada ao programa de pós-graduação em antropologia social da UFRGS, Porto Alegre, 2003.

HARTOG, François. Tempo e Patrimônio. Varia História, Belo Horizonte, 2006 
HEYMANN, Luciana Quillet. Arquivos e a interdisciplinaridade: algumas reflexões. Seminário CPDOC 35 anos: a interdisciplinaridade nos estudos históricos. Rio de Janeiro, 2008.

LANGDOM, Esther. Performance e sua diversidade como paradigma analítico: a contribuição da abordagem de Bauman e Briggs. Ilha Revista de Antropologia, Universidade Federal de Santa Catarina, Florianópolis, 2006

LEAL, Caroline. Vozes carnavalescas: Construções identitárias através das escritas de si. Revista Litteris, São Paulo, 2009.

LIMA, Andréa da Gama. O legado da escravidão na formação do patrimônio cultural jaguarense. Dissertação de mestrado apresentada ao Programa de Pós-graduação em Memória Social e Patrimônio Cultura da Universidade Federal de Pelotas, Pelotas, 2010.

LEÃO, José. FREITAS, Joseania. Brincantes do carnaval: marcas de africanidade em trânsito no Brasil - Caribe - Brasil. Anais do V simpósio internacional do centro de estudos do Caribe no Brasil. Salvador, 2008.

MALINOWSKI, Bronislaw. Capítulo I: Objetivo, método e alcance desta pesquisa. In: Argonautas do Pacífico Ocidental. Editora Abril, São Paulo, 1978.

NUNES, Juliana dos Santos. Entre comparsas e cordões: o caso do União da Classe. II Encontro Internacional de Ciências Sociais, Pelotas, 2010.

Músicos e operários dividindo o mesmo coreto: banda do círculo operário e cordão União da Classe numa possível relação. Seminário Internacional Bioma Pampa, Jaguarão, 2009.

NOGUEIRA, Antônio Gilberto Ramos. Diversidade de sentidos do patrimônio cultural: uma proposta da trajetória de reconhecimento da cultura afro-brasileira como patrimônio nacional. Anos 90, Porto Alegre, 2008.

OLIVEIRA, Fernanda. Raça, sociabilidade e identidade num clube pelotense: Clube carnavalesco negro Fica Ahí Pra ir Dizendo (1938-1943). Monografia apresentada ao curso de Licenciatura em História da Ufpel, Pelotas, 2008.

ORTIZ, Renato. Memória coletiva e sincretismo científico: as teorias raciais do século XIX. Cadernos CERU n ${ }^{\circ}$ 17, 1982.

PARANHOS, Adalberto. A música popular e a dança dos sentidos: distintas faces do mesmo. Revista Artcultura, Uberlândia, 2006.

PRASS, Luciana. Saberes musicais em uma bateria de escola de samba. Uma etnografia entre os Bambas da Orgia, cap. I Entre os Bambas da Orgia, p. 23-53. Editora UFRGS, Porto Alegre, 2004. 
POUTIGNAT, Philippe \& STREIFF-FENART, Jocelyne. Teorias da Etnicidade. Editora UNESP, São Paulo, 1998

ROCHA, Ana Luiza. ECKERT, Cornélia. Imagens do tempo nos meandros da memória: por uma etnografia da duração. Revista Iluminuras, UFRGS, Porto Alegre, 2000.

ROSA, Marcus. Quando Vargas Caiu no Samba; Dissertação de mestrado apresentada ao programa de pós-graduação em História da UFRGS, Porto Alegre, 2008.

SEEGER. Anthony. "Etnografia da Música". In: Myers, Helen. Ethnomusicoly. An Introduction. Londres, 1992.

SIMSON, Olga Von. Carnaval em Branco e Negro. Carnaval popular paulistano 1914-1988. Campinas: Editora Unicamp, São Paulo, 2007.

SHUCH, Patrice. Etnia e classe social: uma análise comparativa, Porto Alegre, 2002.

TINHORÃO, José Ramos. Pequena História da Música Popular. Editora: Círculo do Livro, São Paulo, 1975.

Os sons dos negros no Brasil. Cantos, danças, folguedos: origens. Editora 34, São Paulo, 2008.

VALLADARES, Licia. Os dez mandamentos da observação participante. Revista Brasileira de Ciências Sociais, v. 22, nº 63, São Paulo, 2007.

VELHO, Gilberto. A utopia urbana. In: estudo de antropologia social, Rio de Janeiro, 1982.

VIANA, Letícia. Legislação e preservação do patrimônio imaterial. Perspectivas, experiências e desafios para a salvaguarda da cultura popular. Textos Escolhidos de Cultura e Arte Populares, Rio de Janeiro, 2004.

ZANINI, Maria Catarina. Pertencimento étnico e territorialidade: italianos na região central do Rio Grande do Sul (Brasil). REDES, V.13, n 3, p. 140-163, Santa Cruz do Sul, 2008.

\section{FONTES CONSULTADAS}

Atas do Círculo Operário Jaguarense de 1911 - 1922

Atas do Clube Social 24 de Agosto - 1955 - 1970

Jornal “A Situação" de 1918 - 1960

Entrevista com Mestre Vado - realizada em 2008

Entrevista com Nergipe Machado - realizada em 2009

Entrevista com D. Cibele - realizada em 2010

Entrevista com D. Tereza de Los Angeles - realizada em 2010

Estatutos do Clube Social 24 de Agosto de 1964

Estatutos do Círculo Operário Jaguarense de 1948 
Fotos do Cordão União da Classe - pertencentes aos acervos particulares de D. Aldaci, D. Tereza e ex-presidente do Clube Getúlio (in Memorian)

Site sobre candombe - www.candombe.com - visitado em janeiro e outubro de 2010.

Diários de Campo de 2009, 2010 e 2011. 